\title{
Management of type 2 diabetes: now and the future
}

\author{
Authors: Simon Edeghere ${ }^{A}$ and Patrick English ${ }^{B}$
}

There are about 4.7 million people living with diabetes mellitus in the UK and $90 \%$ have type 2 diabetes mellitus (T2DM). This burden will only get worse as there are currently about 12.3 million more at risk of T2DM. Moreover, up to $30 \%$ of diagnosed patients already have eye, foot, kidney or nerve complications. This impacts the NHS considerably as it spends about $£ 10$ billion annually on diabetes ( $80 \%$ on complications alone). Atherosclerotic cardiovascular disease (ASCVD), the leading cause of death in diabetes, contributes significantly to this.

Therefore, there is significant emphasis on the prevention of T2DM especially in at-risk groups with the setting up of initiatives like the Diabetes Prevention Programme. When prevention fails, it is essential to commence glucose-lowering agents to reduce the burden of disease, prevent associated complications and improve quality of life.

A patient-centred approach is required to ensure efficacy of treatment strategies and the presence of co-morbidities such as cardiovascular and renal disease should be considered.

\section{Introduction}

There are about 4.7 million people living with diabetes mellitus in the UK and $90 \%$ have type 2 diabetes mellitus (T2DM). ${ }^{1}$ This burden will only get worse as there are currently about 12.3 million more at risk of T2DM. Moreover, up to $30 \%$ of diagnosed patients already have eye, foot, kidney or nerve complications. ${ }^{1}$ This impacts the NHS considerably as it spends about $£ 10$ billion annually on diabetes (80\% on complications alone). ${ }^{1}$ Atherosclerotic cardiovascular disease (ASCVD), the leading cause of death in diabetes, contributes significantly to this. ${ }^{2}$

Therefore, there is significant emphasis on the prevention of T2DM especially in at risk groups with the setting up of initiatives like the Diabetes Prevention Programme. When prevention fails, it is essential to commence glucose-lowering agents to reduce the burden of disease, prevent associated complications and improve quality of life.

A patient-centred approach is required to ensure efficacy of treatment strategies and the presence of co-morbidities such as cardiovascular and renal disease should be considered. ${ }^{3}$

Authors: ${ }^{\mathrm{A}}$ specialist registrar endocrinology, diabetes and general medicine, Plymouth Hospitals NHS Trust, Plymouth, UK; ${ }^{B}$ consultant in diabetes, endocrinology, general and acute medicine, Plymouth Hospitals NHS Trust, Plymouth, UK
The goal of this article is to introduce the non-specialist clinician to the newer agents used in the management of T2DM and advise on drug choice based on clinical and cost effectiveness. This would be illustrated with a clinical case with reference made to the National Institute for Health and Care Excellence (NICE) and the American Diabetes Association (ADA) / European Association for the Study of Diabetes (EASD) guidelines. The focus will be on noninsulin and non-surgical treatment options.

\section{Case illustration}

A 60-year-old male with T2DM for 10 years who takes metformin, $1 \mathrm{~g}$ twice daily (other medications include aspirin $75 \mathrm{mg}$, ramipril $2.5 \mathrm{mg}$ and atorvastatin $80 \mathrm{mg}$ ) was seen for his annual diabetes check.

He has a past medical history of ischaemic heart disease with a previous myocardial infarction and percutaneous coronary intervention with stenting.

Examination findings included a body mass index of $31 \mathrm{~kg} / \mathrm{m}^{2}$ and blood pressure of $128 / 78 \mathrm{mmHg}$ with his most recent glycated haemoglobin ( $\mathrm{HbA1c}$ ) being $62 \mathrm{mmol} / \mathrm{mol}$ (target $\leq 53 \mathrm{mmol} / \mathrm{L}$ ) and estimated glomerular filtration rate $65 \mathrm{~mL} / \mathrm{min} / 1.73 \mathrm{~m}^{2}$.

This man clearly needed optimisation of his glucose-lowering medication but would also benefit from an agent with

\section{Key points}

The UK prevalence of type 2 diabetes mellitus (T2DM) is rising and costing the NHS significantly.

Optimising glycaemic control promptly can confer long lasting protection from microvascular complications.

Metformin remains the first-line glucose-lowering agent in T2DM.

Sodium-glucose co-transporter- 2 inhibitors and glucagon-like peptide-1 agonists have benefit in atherosclerotic cardiovascular disease and heart failure and confer renal protection.

These agents should be added to metformin promptly in at risk groups with patient-specific glycated haemoglobin targets set.

KEYWORDS: Type 2 diabetes mellitus, cardiovascular disease, chronic kidney disease, heart failure, glucose-lowering agents 
cardiovascular and renal protection. We would suggest the addition of either a sodium-glucose co-transporter-2 inhibitor (SGLT-2i) or glucagon-like peptide-1 (GLP-1) receptor agonist with proven evidence of cardiovascular and renal benefit. These agents can also promote weight loss, which would also be beneficial.

However, patient preference and cost effectiveness of medication should be considered when choosing glucose-lowering agents.

We would therefore suggest introducing empagliflozin $10 \mathrm{mg}$ or dapagliflozin $10 \mathrm{mg}$ once daily to his medication and he should have a repeat $\mathrm{HbA1c}$ in 3 months to assess the efficacy of treatment as well as monitoring of his renal function.

\section{Discussion: glucose-lowering agents}

The level of $\mathrm{HbA} 1 \mathrm{c}$ is an estimate of mean blood glucose over a 3 month period. ${ }^{4} \mathrm{HbA} 1 \mathrm{c}$ targets have been set by different national and international guidelines to determine when to optimise treatment. These targets should be patient centred and treatment individualised to ensure success. This is important because there is evidence showing that if glycaemic control is optimised especially around the time of diagnosis, the effects in preventing microvascular complications can be long lasting. ${ }^{5}$

The choice of glucose-lowering agent used in T2DM is dependent on a number of factors including patient preference, drug efficacy, presence of co-morbidities and side effect profile (eg weight gain or hypoglycaemia). ${ }^{6}$ Traditionally, due to the close association of T2DM and obesity, medication that are either weight neutral or those that promote weight loss are preferred (see Table 1 for commonly used glucose-lowering agents).
Reviewing the case illustration, the patient is obese with ASCVD, early stage renal impairment and sub-optimal glycaemic control. Optimising his glucose-lowering medication should factor all these and the most clinical and cost-effective agent should be selected using evidence based medicine.

There is now evidence showing that certain SGLT-2i and GLP-1 receptor agonists have beneficial cardiovascular protection in ASCVD and heart failure (HF) and can reduce the progression of chronic kidney disease (CKD).

Empagliflozin has shown a $38 \%$ risk reduction in cardiovascular deaths (reduced hazard ratio (HR) 0.62; $95 \%$ confidence interval (CI) 0.49-0.77; $p<0.001$ ) in people with T2DM and established ASCVD. ${ }^{7}$ Also, canagliflozin demonstrated a reduction in threepoint major adverse cardiovascular events (MACE; HR 0.86; $95 \%$ CI 0.75-0.99; $p=0.02$ ). ${ }^{8}$ Furthermore, dapagliflozin was proven to reduce cardiovascular death and hospitalisation due to heart failure (HR 0.83; 95\% CI 0.73-0.95; $p=0.005) .{ }^{9}$ This effect might be related to blood pressure lowering or effects on vascular endothelium as it occurred irrespective of improvement in $\mathrm{HbA} 1 \mathrm{c}$.

It should be noted that there was no significant reduction in cardiovascular death or hospitalisation due to heart failure in patients without established ASCVD. One could argue that if the patient in the illustrated case did not have ASCVD, then a dipeptidyl peptidase- 4 inhibitor (DPP-4i) may have been an appropriate addition to his medication.

Furthermore, liraglutide and semaglutide have both shown statistically significant reduction in three-point MACE with the former reducing $C V$ death and the latter reducing non-fatal strokes, respectively. ${ }^{10,11}$ Canagliflozin and semaglutide reduce the

Table 1. Common glucose-lowering agents. Data derived from meta-analyses and British National Formulary

\begin{tabular}{|c|c|c|c|c|c|c|}
\hline Drug class (example) & $\begin{array}{l}\text { Glycated haemoglobin } \\
\text { reduction }\end{array}$ & $\begin{array}{l}\text { Effect on } \\
\text { weight }\end{array}$ & Side effects & $\begin{array}{l}\text { Cardiovascular } \\
\text { benefit }\end{array}$ & $\begin{array}{l}\text { Renal } \\
\text { benefit }\end{array}$ & Monthly cost \\
\hline Biguanide (metformin ${ }^{a}$ ) & $\begin{array}{l}0.8-1.0 \% \\
(9-12 \mathrm{mmol} / \mathrm{mol})\end{array}$ & Neutral & Gastrointestinal & Yes & $N / A$ & $\begin{array}{l}£ 3.20 \text { or } € 4.26 \\
\text { modified release }\end{array}$ \\
\hline $\begin{array}{l}\text { Sulphonylurea (gliclazide, } \\
\text { glibenclamide) }\end{array}$ & $\begin{array}{l}0.8-1.1 \% \\
(9-22 \mathrm{mmol} / \mathrm{mol})\end{array}$ & $\begin{array}{l}\text { Weight } \\
\text { gain }\end{array}$ & Hypoglycaemia & $\mathrm{N} / \mathrm{A}$ & $\mathrm{N} / \mathrm{A}$ & $\begin{array}{l}£ 1.63 \text { or } £ 3.27 \\
\text { modified release }\end{array}$ \\
\hline $\begin{array}{l}\text { Thiazolidinedione } \\
\text { (pioglitazone) }\end{array}$ & $\begin{array}{l}0.5-0.7 \% \\
(6-8 \mathrm{mmol} / \mathrm{mol})\end{array}$ & $\begin{array}{l}\text { Weight } \\
\text { gain }\end{array}$ & $\begin{array}{l}\text { Fluid retention } \\
\text { Osteoporosis } \\
\text { Bladder cancer }\end{array}$ & No & $\mathrm{N} / \mathrm{A}$ & $£ 1.84$ \\
\hline $\begin{array}{l}\text { Dipeptidyl peptidase-4 } \\
\text { inhibitors (vildagliptin, } \\
\text { sitagliptin, saxagliptin, } \\
\text { linagliptin) }\end{array}$ & $0.4 \%(5 \mathrm{mmol} / \mathrm{mol})$ & Neutral & $\begin{array}{l}\text { Cough } \\
\text { Nasopharyngitis } \\
\text { Pancreatitis }\end{array}$ & N/A & No & $£ 26.60-£ 33.26$ \\
\hline $\begin{array}{l}\text { Sodium-glucose } \\
\text { co-transporter-2 } \\
\text { inhibitor (canagliflozin, } \\
\text { dapagliflozin, }^{a} \\
\text { empagliflozin, }^{a} \\
\text { ertugliflozin) }\end{array}$ & $0.4 \%(5 \mathrm{mmol} / \mathrm{mol})$ & Loss & $\begin{array}{l}\text { Urinary tract infections } \\
\text { Genital candidiasis }\end{array}$ & Yes & Yes & $£ 36.59-£ 39.20$ \\
\hline $\begin{array}{l}\text { Glucagon-like peptide-1 } \\
\text { receptor agonists } \\
\text { (dulaglutide, exenatide, } \\
\text { liraglutide, }^{a b} \text { lixisenatide, } \\
\text { semaglutide }^{a b} \text { ) }\end{array}$ & $\begin{array}{l}0.5-0.7 \% \\
(6-8 \mathrm{mmol} / \mathrm{mol})\end{array}$ & Loss & $\begin{array}{l}\text { Gastrointestinal } \\
\text { Pancreatitis }\end{array}$ & Yes & Yes & $£ 73.25$ \\
\hline
\end{tabular}


development and progression of albuminuria thereby preventing the progression of CKD. ${ }^{9,11}$

However, despite the efficacy of these agents, metformin remains the first-line drug for the management of T2DM. It has been shown to reduce diabetes related deaths; all-cause mortality and the development of myocardial infarction. ${ }^{12}$ It is relatively well tolerated, weight neutral and is unlikely to cause hypoglycaemia.

Although there are some instances when its use is not appropriate such as in advanced CKD or intolerance due to gastrointestinal side effects. NICE guidelines then recommend either a DPP-4i, pioglitazone or a sulphonylurea (SU) instead. ${ }^{13}$ SGLT-2is are only to be considered if a SU is not tolerated or otherwise inappropriate for the patient and the other option would have been a DPP-4i.

The Scottish Intercollegiate Guidelines Network (SIGN) also have similar recommendations; if metformin is contraindicated they suggest an SU instead. ${ }^{14}$ SGLT-2is are only commenced when an $\mathrm{SU}$ is not tolerated, this could be a potentially missed opportunity to appropriately commence patients with ASCVD on an SGLT-2i or GLP-1 agonist. They recommend an SGLT-2i as second-line treatment if metformin does not achieve target $\mathrm{HbA} 1 \mathrm{c}$ and a GLP1 agonist as third-line. GLP-1 agonist use may be limited because they are given via subcutaneous injections and cost more than standard oral treatment.

In contrast to NICE and SIGN, ADA and EASD recommend starting treatments with proven efficacy in ASCVD, CKD and $\mathrm{HF}$ in at-risk groups sooner. ${ }^{15}$ The ADA/EASD guidelines advice metformin as first-line but suggest including an SGLT-2i or GLP-1 even if patients are at HbA1c target. This would involve reviewing patient specific targets to ensure they receive the added cardiovascular and/or renoprotective benefits without compromising their glycaemic control.

Therefore, it may be appropriate to add an SGLT-2i to the case patient's medication even if his $\mathrm{HbA1c}$ was $51 \mathrm{mmol} / \mathrm{mol}(6.8 \%)$ due to the cardiovascular and renal benefits conferred. These agents have been shown to be cost effective and would help lessen the economic burden on the NHS in the long term. ${ }^{16}$

We suggest that NICE consider implementing ADA/EASD recommendations to introduce SGLT-2i and GLP-1 agonists sooner in patients with T2DM and ASCVD, CKD or HF when it is appropriate. Rather than focusing on $\mathrm{HbA1c}$ targets and optimising treatment only when glycaemic control is above target, patient-specific treatment plans should involve their cardiovascular and renal co-morbidities.

\section{Conclusion}

Type 2 diabetes is a complex entity that can be associated with multiple end-organ complications if not adequately managed. Lifestyle modification in the form of reduced carbohydrate intake and increased physical activity is fundamental. However, if glucose-lowering treatment is required, metformin remains the first-line treatment but SGLT-2i or GLP-1 agonists should be instituted early in patients with ASCVD, HF or CKD with patientspecific $\mathrm{HbA1}$ c targets set. Using these agents appropriately has been shown to be both clinically and cost effective.

\section{References}

1 Diabetes UK. Us, diabetes and a lot of facts and stats. London: Diabetes UK, 2019. www.diabetes.org.uk/resources-s3/201902/1362B_Facts $\%$ 20and $\%$ 20stats $\% 20$ Update $\%$ 20]an $\% 20$ 2019_LOW\% 20RES_EXTERNAL.pdf.

2 American Diabetes Association. 10. Cardiovascular disease and risk management: standards of medical care in diabetes. Diabetes Care 2019;42(Suppl 1):S103-23.

3 American Diabetes Association. 6. Glycemic targets: standards of medical care in diabetes. Diabetes Care 2018;41(Suppl 1):S55-64.

4 Nathan DM, Singer DE, Hurxthal K, Goodson JD. The clinical information value of the glycosylated haemoglobin assay. N Engl ] Med 1984;310:341-6.

5 Holman RR, Paul SK, Bethel MA, Matthews DR, Neil HA. 10-year follow-up of intensive glucose control in type 2 diabetes. N Engl J Med 2008;359:1577-89.

6 Thrasher J. Pharmacologic management of type 2 diabetes mellitus: available therapies. Am J Cardiol 2017;120(1S): S4-16.

7 Zinman B, Wanner C, Lachin JM et al. Empaglifozin, cardiovascular outcomes, and mortality in type 2 diabetes. N Engl J Med 2015;373:2117-28.

8 Neal B, Perkovic V, Mahafey KW et al. Canaglifozin and cardiovascular and renal events in type 2 diabetes. N Engl J Med 2017;377:644-57.

9 Wiviott SD, Raz I, Bonaca MP et al. Dapagliflozin and cardiovascular outcomes in type 2 diabetes. N Engl J Med 2018;380:347-57.

10 Marso SP, Daniels GH, Brown-Frandsen K et al. Liraglutide and cardiovascular outcomes in type 2 diabetes. N Engl J Med 2016;375:311-22.

11 Marso SP, Bain SC, Consoli A et al. Semaglutide and cardiovascular outcomes in patients with type 2 diabetes. N Engl J Med 2016;375:1834-44.

12 Khurana R, Malik IS. Metformin: safety in cardiac patients. Heart 2010:96:99-102.

13 National Institute for Health and Care Excellence. Type 2 diabetes in adults: management. NICE guideline [NG28]. NICE, 2017. www.nice.org.uk/guidance/ng28. [Accessed 11 July 2019].

14 Scottish Intercollegiate Guidelines Network. SIGN 154: Pharmacological management of glycaemic control in people with type 2 diabetes. SIGN, 2017. www.sign.ac.uk/assets/sign154.pdf [Accessed 11 July 2019].

15 Davies MJ, D'Alessio DA, Fradkin ] et al. Management of hyperglycaemia in type 2 diabetes, 2018. A consensus report by the American Diabetes Association (ADA) and the European Association for the Study of Diabetes (EASD). Diabetologia 2018;61:2461-98.

16 Hong D, Si L, Jiang M et al. Cost effectiveness of sodium-glucose cotransporter-2 (SGLT2) inhibitors, glucagon-like peptide-1 (GLP-1) receptor agonists, and dipeptidyl peptidase-4 (DPP-4) inhibitors: a systematic review. Pharmacoeconomics 2019;37:777-818.

Address for correspondence: Dr Simon Edeghere, Plymouth Hospitals NHS Trust, Endocrinology, Derriford, Plymouth PL6 8DH, UK.

Email: simon.edeghere@nhs.net 


\section{Royal College
of Physicians}

\section{Complex regional pain syndrome in adults}

\section{UK guidelines for diagnosis, referral and management in primary and secondary care}

Published by the Royal College of Physicians, these guidelines concern the diagnosis and management of patients with complex regional pain syndrome (CRPS). They are designed for professionals working in the different health specialties who care for these patients.

Updated in 2018, and published in partnership with over 20 other medical organisations, the guidelines provide information on diagnosis, treatment, management and support for patients in a wide variety of clinical settings.

The report underlines the need for multidisciplinary support to manage CRPS and outlines the four pillars of care that underpin management:

$>$ education

$>$ pain relief

$>$ physical rehabilitation

> psychological intervention.

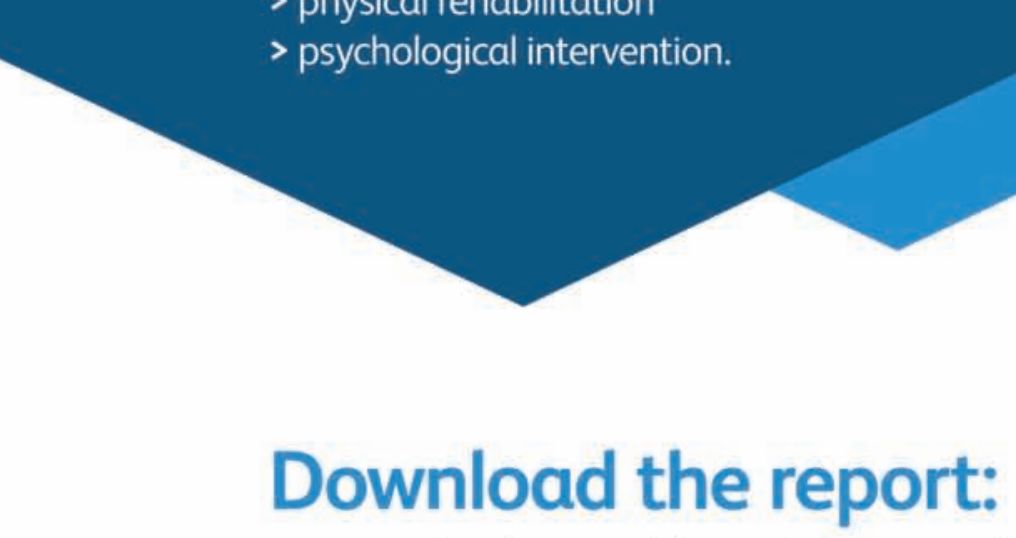

www.rcplondon.ac.uk/complex-regional-pain-syndrome-adults

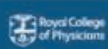

Complex regional pain syndrome in adults

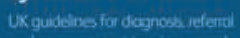
andingrogernertin patinay and 2018 